\title{
Strength in Rotary Friction Welding of Five Dissimilar Nickel-Based Superalloys
}

\author{
This study focuses on which parameters influence \\ welding strength and which do not
}

BY B. S. TAYSOM, C. D. SORENSEN, AND T. W. NELSON

\begin{abstract}
Advanced manufacturing processes improve the cost and quality of goods. Rotary friction welding is a fast, energy-efficient, and reliable joining process for metals, but new applications are hindered by large development costs for each new alloy. Each alloy set has different welding characteristics; therefore, lessons learned from a single alloy are not always broadly applicable. To establish knowledge that is applicable across multiple alloys, a family of different superalloys were welded to discover process trends that were applicable beyond a single alloy set. In this study, weld symmetry did not correlate to weld strength across alloy systems. Some alloys' strongest welds occurred at maximum symmetry, whereas high asymmetry was associated with different alloys' maximum strength. High feed rates, high welding forces, low energy, and low temperatures all resulted in high-strength welds across all alloy and geometry combinations. Tensile strengths greater than $95 \%$ of base-metal strength were recorded for most alloy systems.
\end{abstract}

\section{KEYWORDS}

- Friction Welding • Rotary Friction Welding • Superalloy - Dissimilar Weld • Weld Asymmetry

\section{Introduction}

\section{Background}

Rotary friction welding (FRW) is a solid-state joining process used to join axisymmetric parts (Ref. 1). In FRW, one workpiece is rotated with respect to another, and the two pieces are then pushed together under high axial loads. The pressure and friction create heat, which leads to surface deformation and eventually to a strong metallic joint between the two components. With proper welding parameters, FRW can produce higher-strength, defect-free joints with lower peak temperatures and smaller heat-affected zone (HAZ) regions than fusion-based welding (Refs. 2, 3).

\section{Literature Review}

Welding parameters have a strong influence on final weld properties. Surface cleanliness has a large impact on weld quality, particularly if the surfaces are not prepared well (Refs. 4, 5). Multiple researchers have shown that welding input parameters have a large effect on weld quality (Refs. 6, $7)$. Force is needed both to generate heat and to prevent voids at the weld interface (Refs 6, 7). Excessive temperatures, however, lead to a large HAZ and low strength (Ref. 8 ), and thus trade-offs exist in welding parameters. While symmetry of deformation (and thus flash) is often thought of as desirable in FRW, several studies have not identified uniformity of deformation as a requirement for good bonding (Refs. 6, 9, 10).

While the welding of workpieces with different characteristics is more difficult than that of two identical workpieces, solid-state joining processes have inherent advantages in dissimilar workpiece welding. In fusion welding, both workpieces must be melted, which is problematic for alloys with vastly different melting temperatures. In FRW, workpieces are never melted (Ref. 11), and thus many different alloys can be joined together (Ref. 12, 13). Even alloys with drastically different melting temperatures, such as aluminum and stainless steels, have been successfully welded with FRW (Ref. 10).

Superalloys are often friction welded because of the potential for high-strength welds in demanding environments (Ref. 11). FRW of superalloys presents unique challenges because superalloys are specifically designed not to deform at high temperatures, but hot deformation is the foundation of FRW (Refs. 14-16). Several studies of inertia friction welding (FRW-I) have been performed on low-solvus, high-refractory and MAR-M247 superalloys (Refs. 11, 17-19). For these alloys, increasing the mass of the FRW-I flywheel improved the postweld qualities (Refs. 17, 18). Additionally, avoiding overly long weld times was necessary to prevent cracking in some circumstances (Ref. 19). While quality of the welds increased, the microstructural changes that led to quality improvements were different due to the fundamental differences of each alloy. Several other studies used Alloy 718 as one of the two joined pieces (Refs. 14-16). Due to the solutionizing of Alloy 718 during welding, there was a reduction of residual stresses 
near the weld interfaces, which is helpful for reducing crack growth and formation (Ref. 15). Because these superalloys are different, the researchers identified different factors as improving or degrading the weld performance according to several different key metrics. The literature as it stands does not coalesce the production of high-quality superalloy friction welds into a few key process parameters.

\section{Objective}

Different alloys behave differently during hot deformation, and, consequently, different factors have been found to correlate with high-quality welds across the wide range of previous research. This work focused on FRW of nickel-based superalloys and used two different weldment geometries. Room temperature tensile strengths for the chosen alloys varied by a factor of $\sim 1.8$, and maximum service temperatures varied by several hundred degrees Celsius. In particular, this study focused on which parameters influence welding strength and which do not. Appropriate normalization of parameters was performed to coalesce material properties from different material groups. The present work sought to determine factors that are applicable across alloys as opposed to trends that are specific to a single alloy.

\section{Experimental Procedures}

Alloy 600, Alloy 625, Alloy 718, Waspaloy ${ }^{\circledR}$, and Udimet ${ }^{\circledR}$ 720 were used in this study (the former three alloys are often known by the trademark name of Inconel ${ }^{\circledR}$ ). Two specimen geometries were used. Solid cylinders were machined with a $25.4 \mathrm{~mm}$ (1.00 in.) diameter, and tubular samples were machined to an outer diameter of $25.4 \mathrm{~mm}$ (1.00 in.) and an inner diameter of $20.3 \mathrm{~mm}$ (0.80 in.) about $25 \mathrm{~mm}$ (1 in.) deep. K-type thermocouples were spot welded onto the exterior of the stationary samples at distances of $1,2,3$, 4 , and $5 \mathrm{~mm}$ away from the interface. Fiducial marks were placed $10 \mathrm{~mm}$ away from the interface to enable measuring the postweld upset of each specimen. The schematic of the sample setup is shown in Fig. 1.

All welds were performed on a TTI RM2 high-stiffness friction stir welding (FSW) machine. The machine was updated with a BOND ${ }^{\mathrm{TM}}$ Technologies B\&R-based controller. A torque meter was attached to the welding bed to hold the lower non-rotating sample and to measure the torque. Other recorded measurements included spindle speed, triaxial forces, thermocouple temperatures, axial position, and velocity. Spindle speed and torque were used to calculate the welding power, which, when integrated over time, resulted in the total welding energy.

Prior to welding, all specimens were brought into contact with $40 \mathrm{kN}$ of force, a zero-position reference was established at $0 \mathrm{kN}$, and the samples were then moved $1 \mathrm{~mm}$ apart. The spindle was started, and the machine moved with a constant feed rate until the total feed $(5 \mathrm{~mm})$ was reached. Starting at about $0.6 \mathrm{~s}$ before the total feed was reached, the spindle decelerated from 1000 to 0 rpm over about $0.4 \mathrm{~s}$.

Welds were performed at feed rates of $0.5,1,2$, and 4 $\mathrm{mm} / \mathrm{s}$, a total feed of $5 \mathrm{~mm}$, and a spindle speed of 1000 $\mathrm{rpm}$. This was done for all of the following alloy/geometry combinations: tube 718 - solid 718, tube 600 - tube 718,

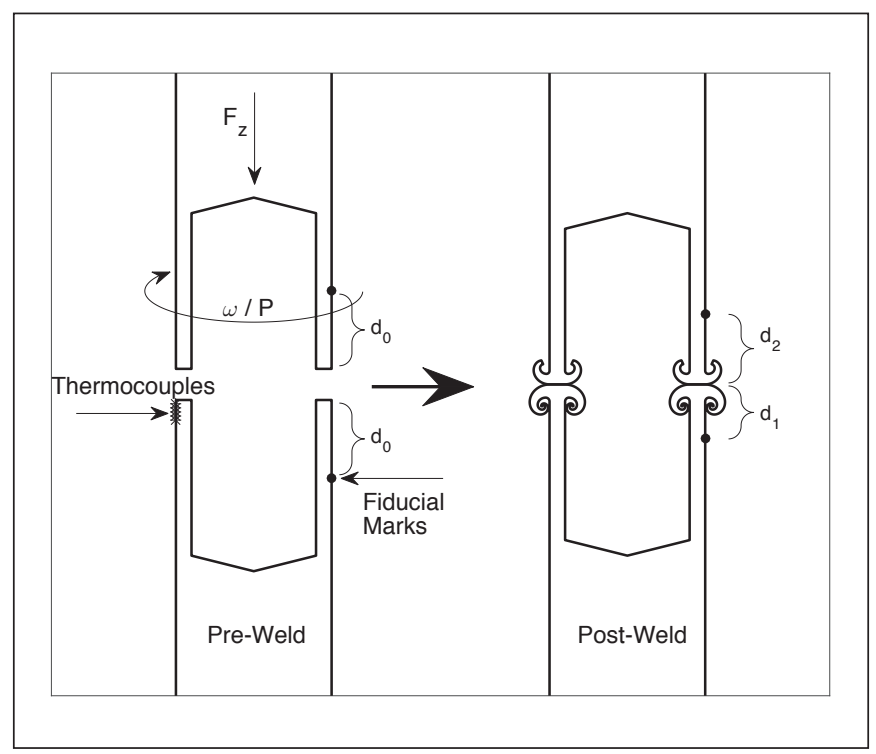

Fig. 1 - Schematic of the sample setup (for tube-tube welds) including locations of thermocouples and fiducial marks.

tube 718 - tube 625, tube 718 - tube Waspaloy, and tube 600 - tube Udimet 720. A few welds were repeated at similar conditions so that the intact interface could be sectioned and polished, and the hardness could be measured using a $20 \times 10$ microhardness grid with a $100-\mu \mathrm{m}$ spacing and 200 $\mathrm{g}$ indent load.

After welding, the distance from the fiducial marks to the final weld interface was measured to calculate the sample upset ratio. The sample upset ratio was calculated as $\left(d_{0}-d_{2}\right)$ / $\left(d_{0}-d_{1}\right)$. As-welded samples were pulled in tension until failure in a $500-\mathrm{kN}$-capacity MTS tensile testing machine. The ultimate tensile strength (UTS) and fracture location were recorded.

Strength and welding force were normalized to allow easier comparisons across alloys with different strengths. Normalized strength is also known as joint efficiency and indicates how strong a joint is compared to its theoretical maximum. Normalizing the welding force allowed the necessary applied force to be compared to other parameters across different alloy systems.

Normalized strength was calculated as the ratio of aswelded UTS divided by the base metal UTS of the weaker alloy at room temperature. Normalized force was calculated by dividing the peak welding force by the original cross-section area, and then dividing this by the base metal UTS of the weaker alloy at room temperature. The room temperature UTS values used for this were 860, 1105, 1450, 1275, and $1110 \mathrm{MPa}$ for Alloy 600, Alloy 625, Alloy 718, Waspalloy, and Udimet, respectively.

\section{Results}

The full time-series data for the tubular weld between $\mathrm{Al}$ loys 600 and 718 at $0.5 \mathrm{~mm} / \mathrm{s}$ is shown in Fig. 2. The trends in this weld were typical of what is seen in the other welds, although magnitude and slope dramatically changed with the processing conditions and alloy. One notable difference was that one or more thermocouples failed in most of the 

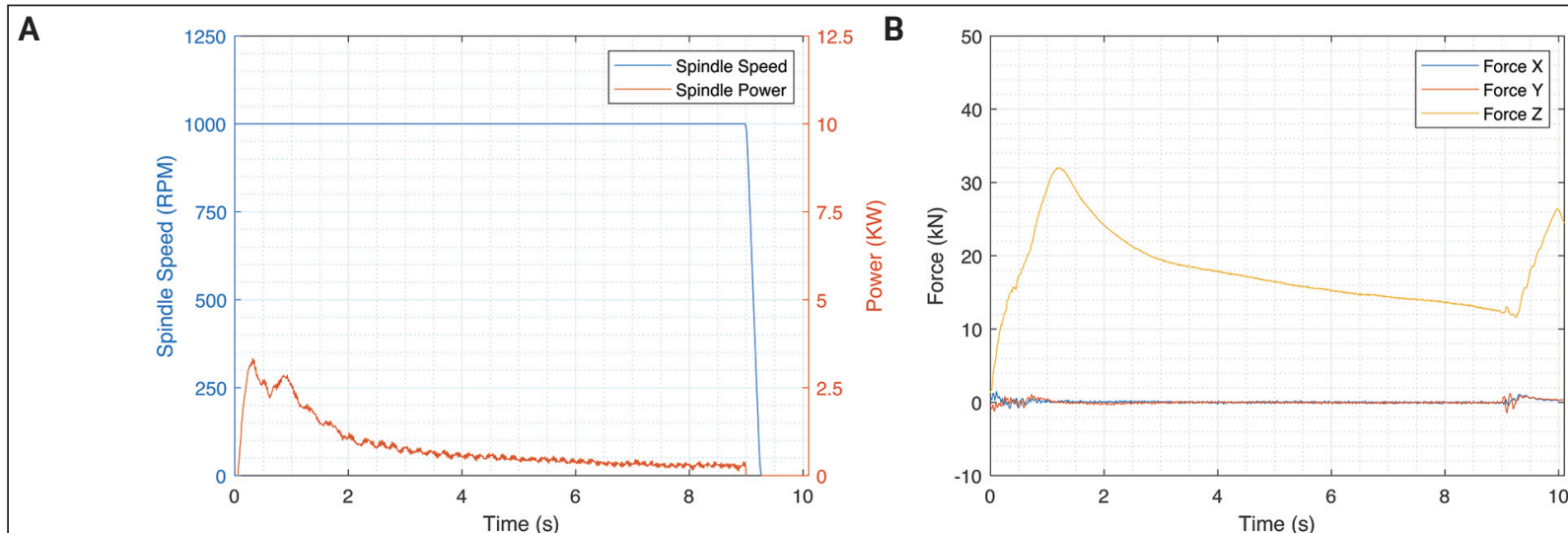

C
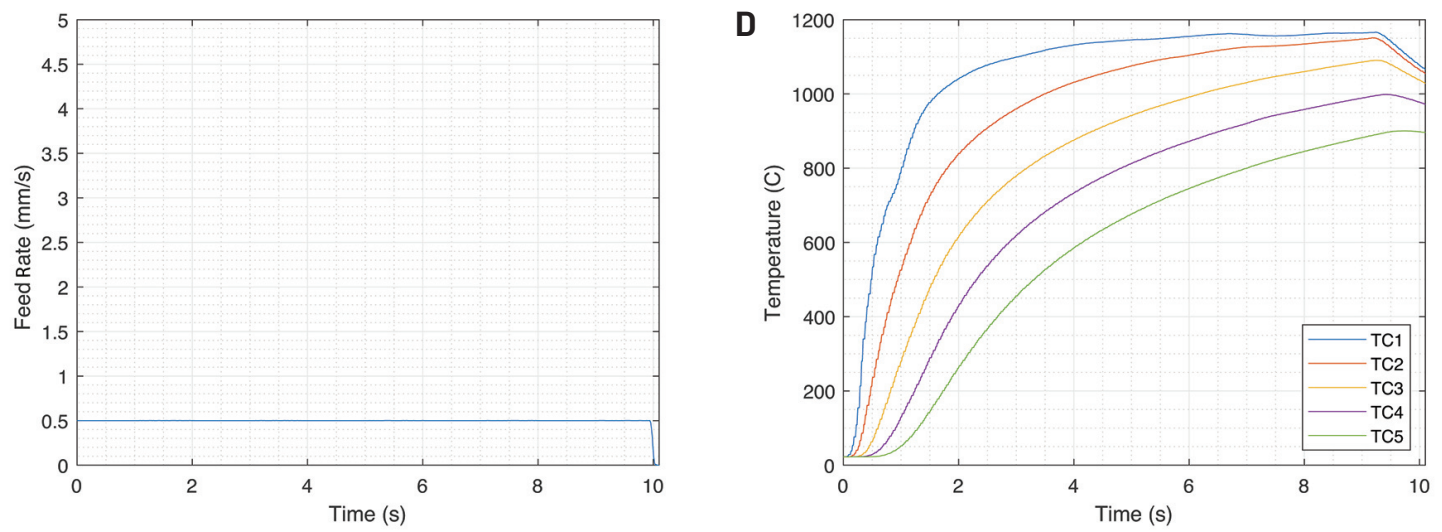

Fig. 2 - Process data for the $0.5-\mathrm{mm} / \mathrm{s}$ Alloy 600 to Alloy 718 tube weld. A - Spindle speed and power; B - force; $\mathrm{C}$-feed rate; $D$ - temperature.

welds, with the thermocouple nearest the weld interface most likely to fail. For this reason, several of the peak temperatures in Table 1 had to be extrapolated or estimated from the rest of the data set.

The alloy and geometry system, feed rate, peak normalized welding force, peak temperature, total weld energy, upset asymmetry, and normalized strength are shown for all 20 welds in Table 1 . In some cases, the thermocouple(s) nearest the weld interface broke off prematurely, and the significant figures of temperature in Table 1 are representative of the level of confidence in the estimated peak temperature - the one-place values indicate the measured value of the maximum temperature, the ten-place values indicate an estimation with confidence within $20^{\circ} \mathrm{C}$, and the 100-place values indicate an estimation with confidence within $100^{\circ} \mathrm{C}$.

Statistical analysis was performed on the data in Table 1. Feed rate, temperature, force, energy, and asymmetry were each used individually to predict the weld strength. The pvalues and $R^{2}$ values for each model are shown in Table 2. A plot of the best-fitting model is shown in Fig. 3, with the worst-fitting model shown in Fig. 4.

Feed, force, energy, and temperature are each statistically significant for predicting strength at the $99 \%$ confidence level. These four parameters also all correlate together, as shown for force and feed rate in Fig. 5. Due to this, they are covariant, meaning their predictive effects significantly overlap, and using all of them does not result in a much bet- ter model. While a model using only energy to predict strength has an $R^{2}$ of 0.73 and an adjusted $R^{2}$ of 0.72 (which penalizes superfluous descriptive parameters), a model using all four parameters has an $R^{2}$ of 0.78 and an adjusted $R^{2}$ of just 0.72 . For all alloys and geometries studied, the strongest welds occurred at high feed rates, low temperatures, and high welding forces.

Weld upset asymmetry for each alloy changed with operating conditions. Cross sections of welds between Alloys 625 and 718 at different feed rates are shown in Fig. 6. For this alloy pair, upset asymmetry was reduced by welding at higher feed rates. The relationship between weld upset asymmetry and feed rate for all alloy pairs is shown in Fig. 7. The relationship changed greatly between alloy pairs.

In contrast to feed, force, and temperature, the asymmetry of the weld had no statistically significant correlation to the resultant strength. Even when the alloy system was added as an additional descriptive parameter, asymmetry was still statistically insignificant ( $p>0: 5)$. As seen in Fig. 4, no inter-alloy trends existed.

\section{Discussion}

While most FRW is done in a force-control manner, this work was done in a displacement-control manner for two primary reasons. The first is that the FSW machine has ex- 


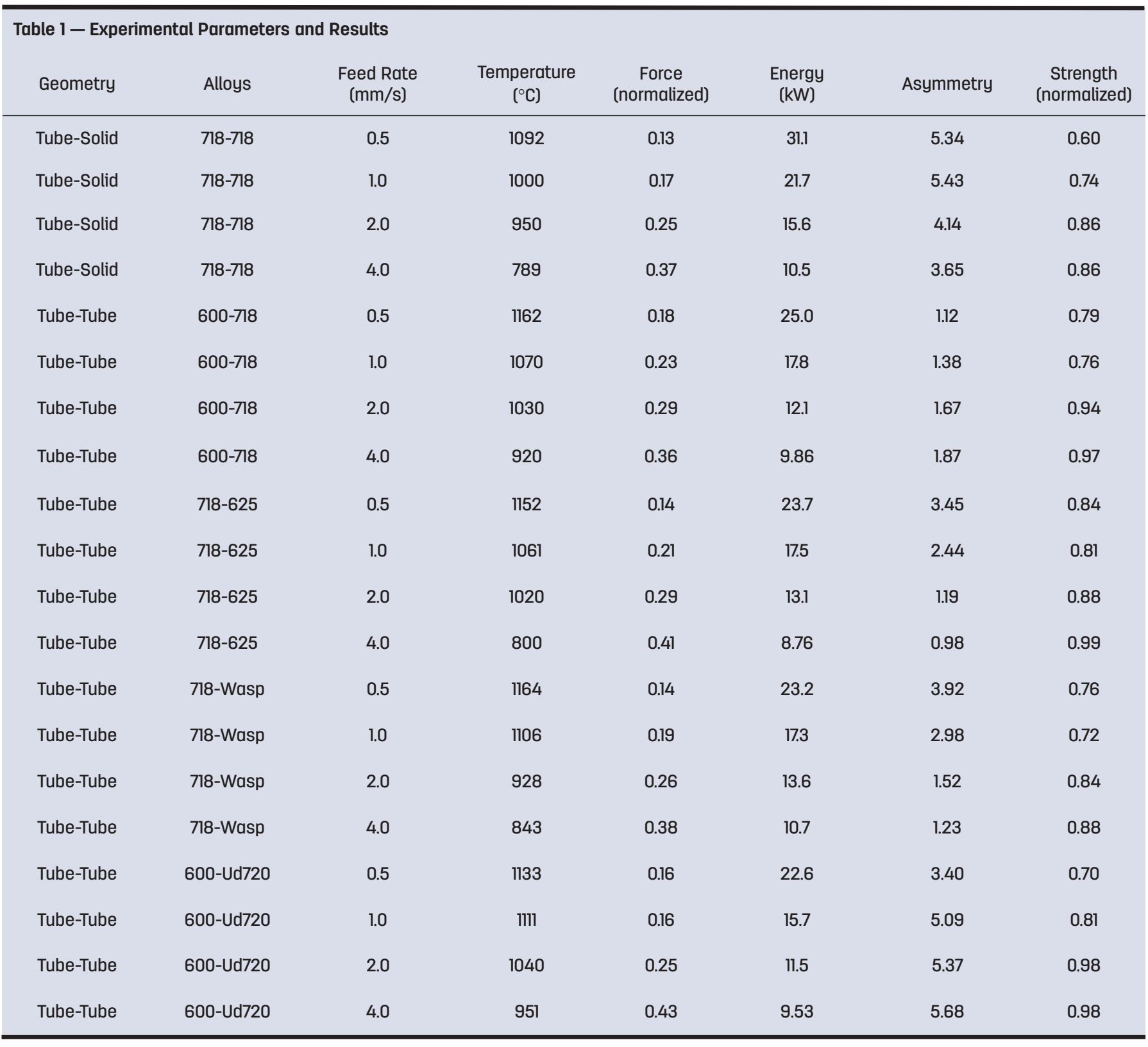

Table 2 - Fit Parameters for Different Models Predicting Weld Strength

\begin{tabular}{ccccr} 
& Feed Rate & Temperature & N. Force & Energy \\
\hline P-Value & T1.2e-4 & $6.7 \mathrm{e}-3$ & $3.8 \mathrm{e}-5$ & $1.5 \mathrm{e}-6$ \\
$\mathrm{R}^{2}$ & 0.57 & 0.34 & 0.62 & 0.33 \\
\hline
\end{tabular}

cellent position and force-control systems, allowing easy control in either mode. The second and more important reason is due to initial power generation and heating. In displacement control, a high initial force occurs as shown in Fig. 2. This higher peak force and power dissipation at the beginning of a weld results in a quicker weld for the same displacement with lower total energy dissipation, and thus has the possibility to reduce the HAZ size.

Figure 8 shows the tensile strength for all five alloys up through moderately hot temperatures. From Fig. 8, it can be seen that while all of the alloys became softer with temperature, not all softened at the same rate. For instance, at room temperature, Udimet 720 had a lower strength than Alloy 718 , but at higher temperatures, Udimet 720 had the highest strength of all the studied alloys. Figure 9 shows the flow stress for four of the alloys in temperature ranges that are more representative of the FRW temperature range. Alloys 718 and 600 had a large strength difference at $900^{\circ} \mathrm{C}$, but 


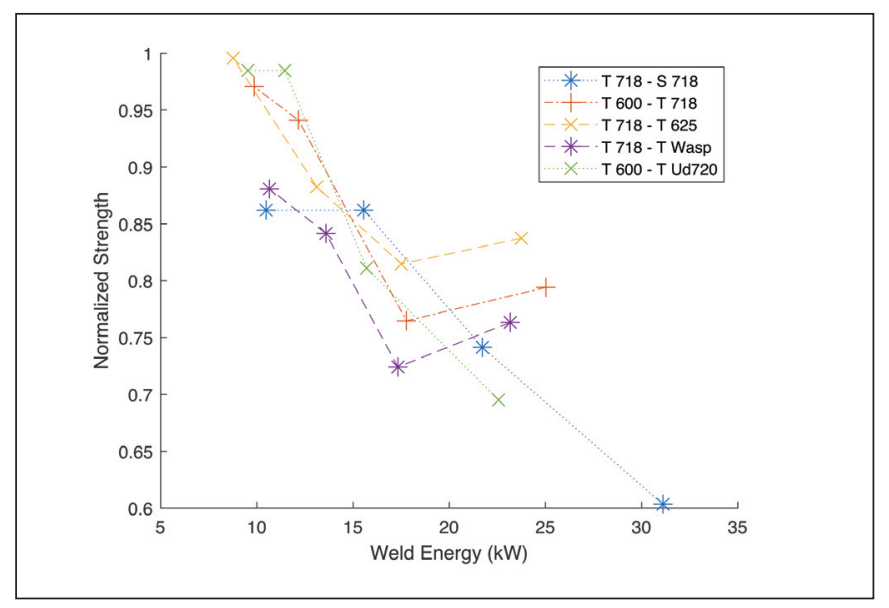

Fig. 3 - Normalized weld strength plotted against total energy used during welding. Strength increased with decreasing total energy.

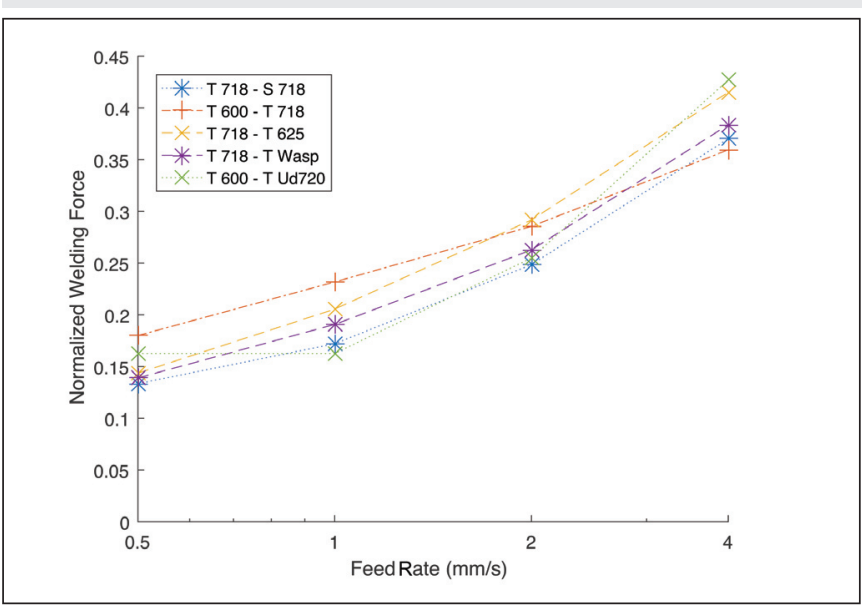

Fig 5 - Normalized peak axial forces vs. feed rate. Force increases with feed rate for all alloy/geometry systems.

this largely disappeared by $1100^{\circ} \mathrm{C}$. The following was also observed in this study: At $920^{\circ} \mathrm{C}$, the upset asymmetry was 1.87 but decreased to 1.12 at $1162^{\circ} \mathrm{C}$.

A difference in instantaneous strength is the root cause of upset asymmetry. The difference in strength can be caused by different alloys (hot strengths) and/or geometries (temperature distribution). Either way, if a strength difference exists, the weaker alloy deforms more than the stronger alloy. This increased deformation increases internal strain rates, leading to strain-rate hardening, which then leads to a balance of forces (but not upset) from workpieces during welding.

It is well established that the surfaces of a friction weld must be clean or must become clean to produce a good bond (Refs. 1, 4). Symmetry of deformation is sometimes believed to be evidence of equal cleaning of both weld surfaces, thus increasing weld strength. This study, however, found no correlation between weld upset symmetry and weld strength that was consistent between multiple alloy/geometry systems.

While upset symmetry/asymmetry did not affect weld strength, high feed rate, high force, low energy, and low temperature were associated with high weld strengths. These correlations held across the different alloy systems

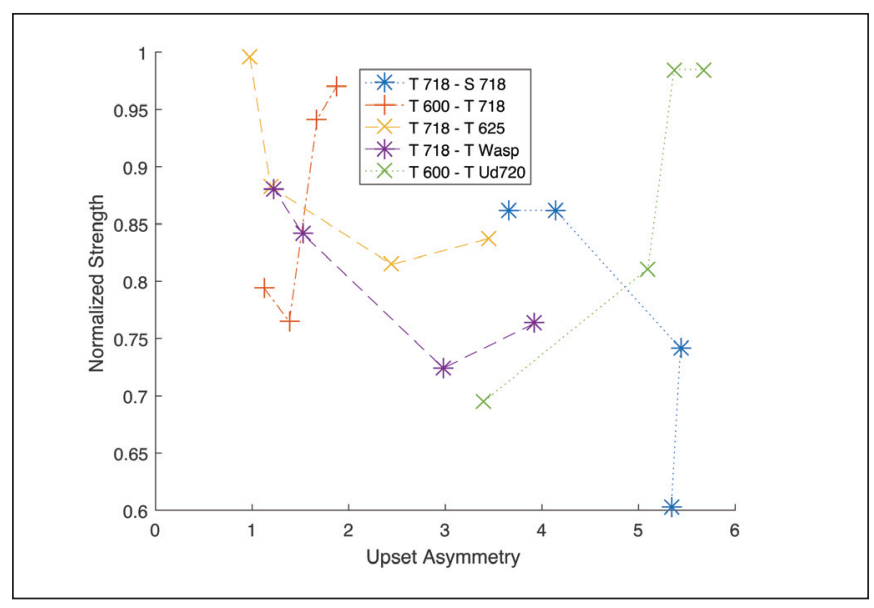

Fig. 4 - Normalized weld strength vs. upset asymmetry. No cross-alloy trends between the strength and asymmetry were evident.

studied. These four parameters are physically and intrinsically linked. A higher feed rate weld resulted in a lower heat energy input per length and a lower temperature. At lower temperatures, alloys had higher strength, resulting in greater force needed to keep feeding the specimens at that feed rate.

The microhardness results in Fig. 8 show why these four parameters lead to better outcomes. By reducing the total time, energy, and temperature (i.e., by welding at $4 \mathrm{~mm} / \mathrm{s}$ vs. $1 \mathrm{~mm} / \mathrm{s}$ ), the HAZ in Alloy 718 was reduced both in size and severity. Alloy 718 is a precipitation-strengthened alloy, so the lower time-at-temperature reduced the amount of annealing near the weld interface. The rate of cool down postwelding did not allow for reprecipitation, so any loss of precipitation hardening was permanent without a postweld heat treatment. Alloy 600, on the other hand, can only be strengthened by work hardening. Thus, a lower temperature and a higher deformation pressure also resulted in a higher interface strength in Alloy 600.

A good friction weld can only occur once the surface is ready to form a new metallic bond: when the roughness, contaminants, and oxides are all expelled or sufficiently diffused away from the original interface. If this does not occur, the weld will always be of poor quality and limited by the interface defects; in this scenario, the HAZ is of less importance. Once the surface has been completely cleaned, further cleaning is completely unnecessary. Consequently, uniform or symmetric deformation is not needed per se: Sufficient deformation must occur in both workpieces to clean the interface.

FRW strength is always determined by the worst of two primary factors: bonding and metallurgical strength. Cleaning of the interface is necessary to create a bond, and pressure and temperature further encourage complete bonding. Metallurgical strength is limited by the base metals and typically by an adverse HAZ, which may be present. Creating a full bond is of primary importance, and once a full bond occurs, process optimization increases weld quality. For these reasons, high force, low-to-moderate energies and temperatures, and low cycle times lead to the highest strength welds, regardless of the dissimilar alloy system used. 


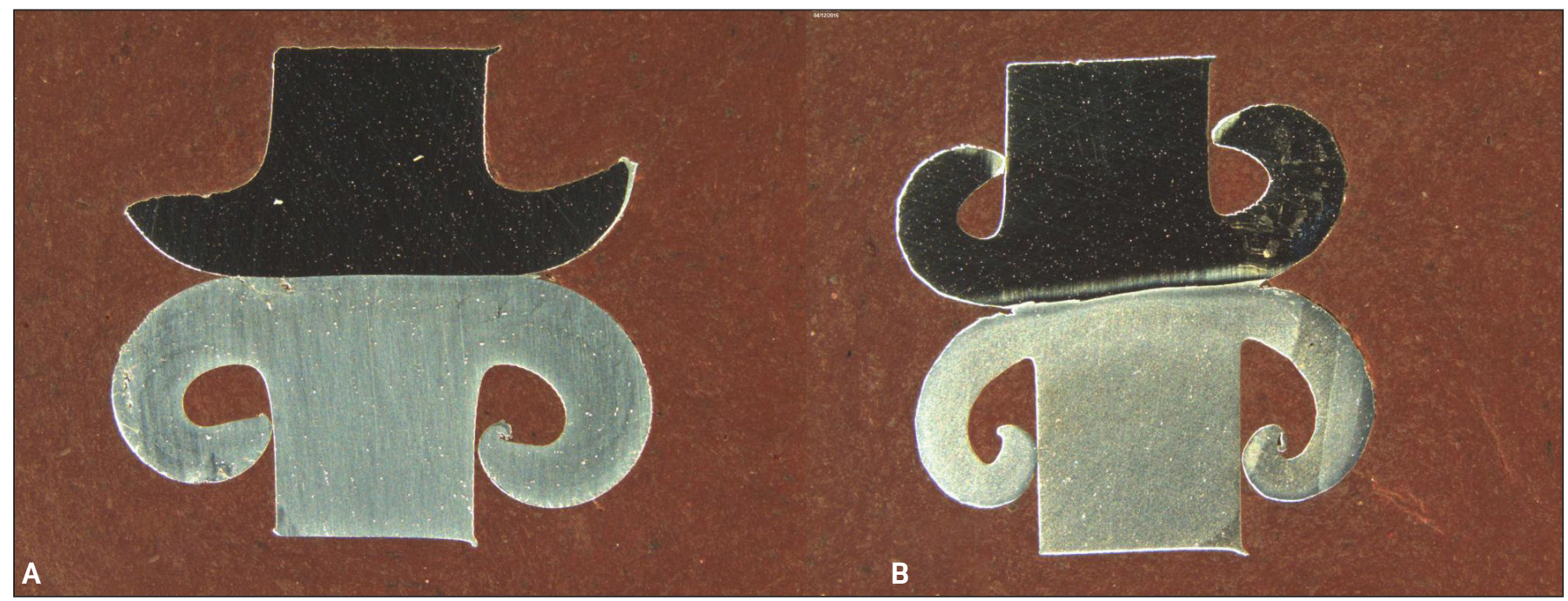

Fig. 6 - Cross section of welds between Alloys 625 (top, black) and 718 (bottom, gray). As the feed rate changed from about 1 $\mathrm{mm} / \mathrm{s}(\mathrm{A})$ to $4 \mathrm{~mm} / \mathrm{s}(\mathrm{B})$, the level of asymmetry dramatically decreased.

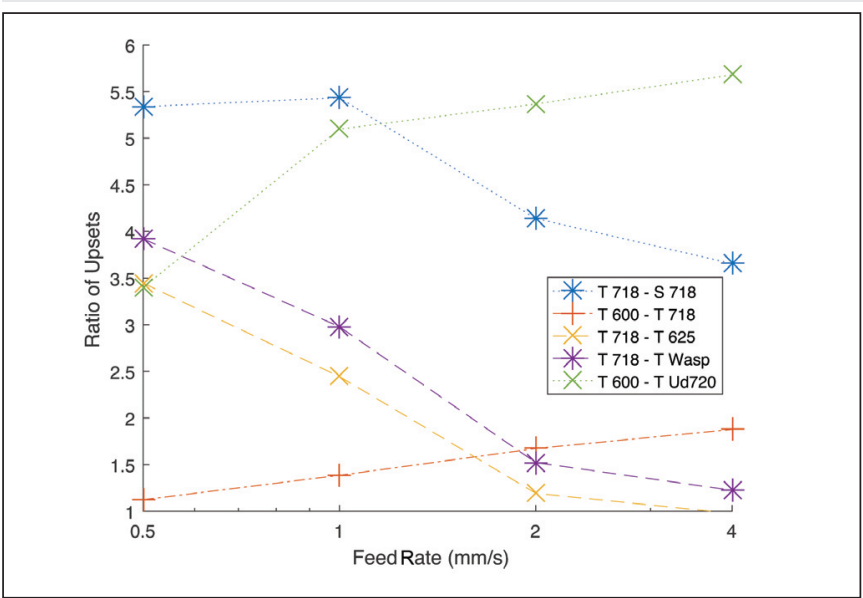

Fig. 7 - Ratio of specimen upsets. Values closer to 1 indicated a more symmetric weld.

\section{Conclusions}

Welds were created in several dissimilar superalloy systems, with strengths up to $99 \%$ of base metal UTS. Sound welds were created in all alloy and geometry systems. High feed rates, high forces, and low temperatures correlated with strong welds across all of the studied weld systems. These factors are linked together by the fundamental physics of the process, so studying them independently is difficult; that is, a slower feed rate leads to more heat accumulation and higher temperatures, which in turn leads to a lower force-carrying capacity.

The upset asymmetry did not have a correlation to weld strength across the studied alloy systems. In three of the five studied combinations, a more asymmetric flash was associated with higher weld strength, whereas the inverse was true in two of five alloy/geometry systems. Reducing upset asymmetry should not be used to assess or improve weld strength. Other factors such as welding force, feed rate, and temperature were far more important for producing high quality welds.

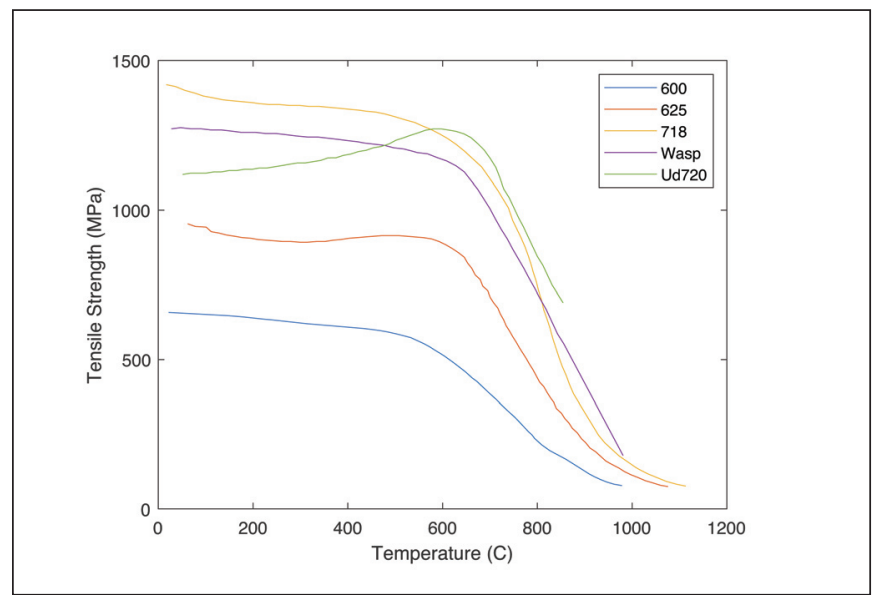

Fig. 8 - Tensile strength of alloys as a function of temperature. Based upon product data from Special Metals.

Fundamentally, a weld will be created when there is sufficient heat and pressure and when surfaces are clean enough; uniformity of deformation is not required for this. After a bond is completely formed, optimizing other process parameters such that the severity of the HAZ is minimized results in the greatest strength welds.

\section{Acknowledgment}

This work was accomplished through a program sponsored by GE Global Research with guidance from Dr. Martin Morra and Nikole Kucza. The authors are very grateful for their material and intellectual support.

\section{References}

1. Li, W., Vairis, A., Preuss, M., and Ma, T. 2016. Linear and rotary friction welding review. International Materials Reviews 61(2): 71-100. DOI: 10.1080/09506608.2015.1109214

2. Bouarroudj, E.-o., Chikh, S., Abdi, S., and Miroud, D. 2017. 


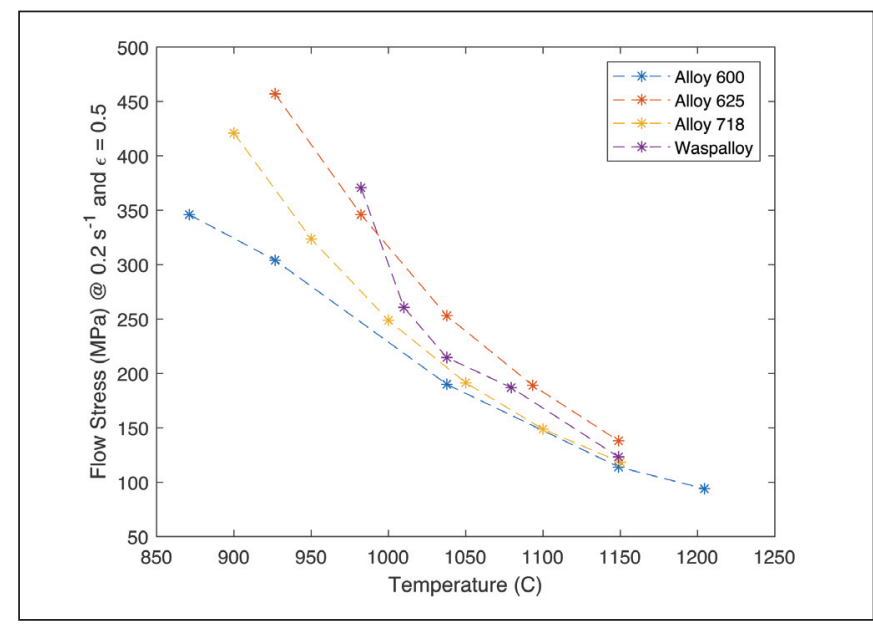

Fig. 9-Flow stress of multiple alloys as a function of temperature, based upon data from the Atlas of Formability by the National Center for Excellence in Metalworking Technology. Flow stress was determined at $0.2 \mathrm{~s}^{-1}$ and $\varepsilon=0: 5$, with interpolation between temperatures and between strain rates for tests conducted at strain rates other than $0.2 \mathrm{~s}^{-1}$.

Thermal analysis during a rotational friction welding. Applied Thermal Engineering 110: 1543-1553. DOI: 10.1016/j.applthermaleng. 2016.09.067

3. Li, P., Li, J., and Dong, H. 2017. Analytical description of heat generation and temperature field during the initial stage of rotary friction welding. Journal of Manufacturing Processes 25: 181-184. DOI: 10.1016/j.jmapro.2016.12.003

4. Bell, R. A., Lippold, J. C., and Adolphson, D. R. 1984. Evaluation of copper-stainless steel inertia friction welds. Welding Journal 63(11): 325-s to 332-s.

5. Workman, G. M., and Nicholas, E. D. 1986. Friction welding aluminium and its alloys to various metals. Metals and Materials 2(3): 138-140.

6. Sahin, M. 2010. Joining of aluminium and copper materials with friction welding. International Journal of Advanced Manufacturing Technology 49(5-8): 527-534. DOI: 10.1007/s00170-009-2443-7

7. Muralimohan, C., Muthupandi, V., and Sivaprasad, K. 2014. Properties of friction welding titanium-stainless steel joints with a nickel interlayer. Procedia Materials Science 5: 1120-1129. DOI: 10.1016/j.mspro.2014.07.406

8. Ahmad Fauzi, M. N., Uday, M. B., Zuhailawati, H., and Ismail, A. B. 2010. Microstructure and mechanical properties of alumina6061 aluminum alloy joined by friction welding. Materials and Design 31(2): 670-676. DOI: 10.1016/j.matdes.2009.08.019

9. Kimura, M., Kusaka, M., Kaizu, K., Nakata, K., and Nagatsuka, K. 2016. Friction welding technique and joint properties of thin-walled pipe friction-welded joint between type 6063 aluminum alloy and AISI 304 austenitic stainless steel. International Journal of Advanced Manufacturing Technology 82(1-4):489-499. DOI: 10.1007/s00170-015-7384-8

10. Sassani, R., and Neelam, J. R. 1988. Friction welding of incompatible materials. Welding Journal 67(11): 264-s to 270-s.

11. Chamanfar, A., Jahazi, M., and Cormier, J. 2015. A review on inertia and linear friction welding of Ni-based superalloys. Metallurgical and Materials Transactions A: Physical Metallurgy and Materials Science 46(4): 1639-1669. DOI: 10.1007/s11661-015-2752-4

12. Kumar, D., Verma, A., Kulshrestha, S., and Singh, P. 2013. Microstructure and mechanical properties of mild steel copper joined by friction welding. International Journal of Mechanical Engineering and Technology 4(5): 295-300.

13. Kimura, M., Nakashima, K., Kusaka, M., Kaizu, K., Nakatani, Y., and Takahashi, M. 2019. Joining phenomena and

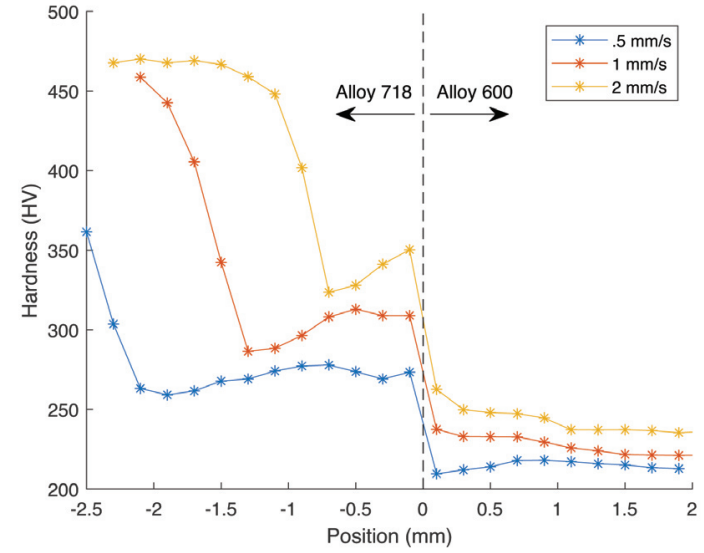

Fig. 10 - Microhardness plot across the weld interface for tube 718 (left) to tube 600 (right) for three different feed rates. Slower feed rates resulted in large HAZ regions in Alloy 718 and a lower minimum hardness in Alloy 600. Deformation is largest closest to the alloy interface, and thus a hardness increase is seen in the 718 HAZ close to the interface in the faster welds.

tensile strength of joint between Ni-based superalloy and heatresistant steel by friction welding. International Journal of Advanced Manufacturing Technology 103(1-4): 1297-1308. DOI: 10.1007/ s00170-019-03611-7

14. Huang, Z. W., Li, H. Y., Preuss, M., Karadge, M., Bowen, P., Bray, S., and Baxter, G. 2007. Inertia friction welding dissimilar nickel-based superalloys alloy 720Li to IN718. Metallurgical and Materials Transactions A: Physical Metallurgy and Materials Science 38(7): 1608-1620. DOI: 10.1007/s11661-007-9194-6

15. Preuss, M., Withers, P. J., and Baxter, G. J. 2006. A comparison of inertia friction welds in three nickel base superalloys. Materials Science and Engineering A 437(1): 38-45. DOI: 10.1016/ j.msea.2006.04.058

16. Daus, F., Li, H. Y., Baxter, G., Bray, S., and Bowen, P. 2007. Mechanical and microstructural assessments of RR1000 to IN718 inertia welds - Effects of welding parameters. Materials Science and Technology 23(12): 1424-1432. DOI: 10.1179/174328407X243997

17. Senkov, O. N., Mahaffey, D. W., and Semiatin, S. L. 2018. A comparison of the inertia friction welding behavior of similar and dissimilar Ni-Based superalloys. Metallurgical and Materials Transactions A: Physical Metallurgy and Materials Science 49(11):

5428-5444. DOI: 10.1007/s11661-018-4853-3

18. Mahaffey, D. W., Senkov, O. N., Shivpuri, R., and Semiatin, S. L. 2016. Effect of process variables on the inertia friction welding of superalloys LSHR and Mar-M247. Metallurgical and Materials Transactions A: Physical Metallurgy and Materials Science 47(8): 3981-4000. DOI: 10.1007/s11661-016-3600-x

19. Senkov, O. N., Mahaffey, D. W., Semiatin, S. L., and Woodward, C. 2014. Inertia friction welding of dissimilar superalloys Mar-M247 and LSHR. Metallurgical and Materials Transactions A: Physical Metallurgy and Materials Science 45(12): 5545-5561. DOI: 10.1007/s11661-014-2512-x

BRANDON SCOTT TAYSOM (brandon.taysom@pnnl.gov) is with Pacific Northwest National Laboratory, Richland, Wash. CARL D. SORENSEN and TRACY W. NELSON are with Brigham Young University, Provo, Utah. 